05

\title{
Эффект самозалечивания откольной повреждаемости
}

\author{
(C) С.Н. Буравова \\ Институт структурной макрокинетики и проблем материаловедения РАН, \\ 142432 Черноголовка, Московская обл., Россия \\ e-mail: svburavova@yandex.ru
}

(Поступило в Редакцию 14 июня 2016 г. В окончательной редакции 7 марта 2017 г.)

Эффект самозалечивания обнаружен при изучении микроструктуры полос локализованной деформации. Показано, что из матричного материала в зону растущей откольной повреждаемости мигрируют элементы внедрения $(\mathrm{O}, \mathrm{C})$ и частицы легирующей фазы. При рассмотрении волновой картины процесса локализации установлено, что формирование полос локализованной деформации сопровождается процессом реверберации, который характеризуется образованием периодически повторяющихся циклов сжатие-растяжение. Слабое затухание реверберации приводит к увеличению длительности импульсного деформирования образца на 2-3 порядка по сравнению с временем начального импульса сжатия.

DOI: 10.21883/JTF.2017.10.44994.1927

\section{Введение}

Полосы локализованной деформации являются предвестником разрушения, отсюда и большой интерес к проблеме залечивания растущей повреждаемости. Воздействие ударной волны на искусственно созданные поры, трещины, полости позволяет выявить процессы, сопутствующие залечиванию. Установлено, что материал вблизи верхушки коллапсирующей поры сильно деформируется [1], степень деформации может превышать $300 \%$ при суммарной аксиальной укороченности образца в 10\%. Характерно, что схлопывание поры сопровождается образованием трещины в направлении нормальном к приложенному сжатию. Интересный результат обнаружен в [2], - оказалось, что критическое напряжение, при достижении которого начинается процесс залечивания, одно и то же как для статического, так и динамического сжатия, и составляет $\sim 100 \mathrm{MPa}$. Залечивание пор малого размера сопровождается образованием сдвиговых полос, длина которых возрастает с ростом амплитуды сжатия. При статическом сжатии такие полосы не наблюдаются, и пластическая деформация в этих условиях проходит гомогенно. Нагружение трещины ударной волной сопровождается образованием полос адиабатического сдвига и вторичных микротрещин в местах локализованного течения у краев трещины, при этом размер трещины уменьшается в направлении распространения ударной волны [3]. В металлах с вязким типом течения (медь, тантал) при компактировании цилиндрических каналов возникают полосы локализованного сдвига вблизи искусственной полости, в то время как для металлов с хрупким типом течения (титан) наблюдается выкрашивание в зоне сдвиговой деформации [4].

Многочисленные исследования микроструктуры полос локализованной деформации характеризуются высоким уровнем описания изменений, происходящих с материалом при взрывном воздействии. Однако причины их вызывающие остаются неизвестными, поскольку исследования проводят на сохраненных образцах после импульсного воздействия без учета формирования структуры в процессе деформирования. На невозможность установления причин изменения структуры обратил внимание Декарли более 30 лет назад [5]. Недавно Майерс в статье о динамической рекристаллизации [6] подтвердил, что такая ситуация будет сохраняться до тех пор, пока не будет создано оборудование, позволяющее изучать изменение структуры в процессе деформирования.

Настоящая работа посвящена исследованию процессов, сопровождающих формирование полос локализованной деформации, для чего микроструктура материала изучается совместно с анализом волновой картины процесса, что позволяет выявить связь формирующейся структуры материала с процессом импульсной деформации.

\section{O температуре в полосах локализованной деформации}

Традиционно считается, что полосы адиабатического сдвига являются результатом теплового разупрочнения металла, которое возникает в результате перехода работы пластической деформации в тепло. Экспериментально измерить температуру в полосах локализации в настоящее время не представляется возможным, поэтому она вычисляется. По разным источникам расчетная температура равна $500^{\circ} \mathrm{C}$ [7], $600^{\circ} \mathrm{C}[8], 800^{\circ} \mathrm{C}$ [9]. Модели деформированного твердого тела Джонсона-Кука (Johnson-Cook) [9] и Зерилли-Амстронга (Zerilli-Armstrong) [10], наиболее часто используемые в расчетах температуры, содержат пять подгоночных параметров. Для описания импульсных процессов такие модели не пригодны [11], поскольку они неадекватно описывают процессы за фронтом ударной волны, не учитывают амплитуду волны, плотность, изменение предела текучести, пластические свойства материала. Регистрируемая инфракрасным детектором 
температура является суммарной по площади (радиус пятна $\sim 45 \mu \mathrm{m})$. Как показано в [12], рост общей температуры перед локализацией совершенно незначительный. Учет теплопроводности среды, соседней с горячим пятном, показывает, что время жизни пятна c начальной температурой $800^{\circ} \mathrm{C}$, составляет всего $1 \mathrm{~ns}[13,14]$. Работа [8] интересна тем, что для расчета температуры не используется модель деформированного тела. Необратимая потеря энергии пластической деформации при импульсном нагружении оценивается на основании геометрической интерпретации законов сохранения, поскольку энергия, переходящая в тепло, не зависит от конкретных механизмов диссипации. На диаграмме $P-V$ (давление-удельный объем) энергия, переходящая в тепло, равна площади между прямой Рэлея-Михельсона и кривой Гюгонио. Именно эта энергия ответственна за остаточный нагрев образца, и для большинства металлов остаточная температура не превышает $10-30^{\circ} \mathrm{C} .\left(\mathrm{Cu}-314^{\circ} \mathrm{C}\right.$; $\mathrm{Al}-311^{\circ} \mathrm{C}$; $\left.\mathrm{Ti}-324^{\circ} \mathrm{C}\right)$. Температура в полосах локализованной деформации при отрицательных давлениях, близких к динамической прочности материала, ниже остаточной температуры и близка к комнатной. Если считать, как делают авторы [8], что необратимая энергия выделяется в тонкой полосе сдвига, то температура нагрева окажется равной $600^{\circ} \mathrm{C}$, что на $250^{\circ} \mathrm{C}$ выше температуры ударного сжатия. Время существования высокой температуры по оценкам [8] составляет несколько наносекунд после прохождения фронта ударной волны. Сомнительно, чтобы столь малая длительность нагрева смогла существенно влиять на формирование макро процесса локализации.

Доказательством высокой температуры внутри полос адиабатического сдвига авторы [15] считают наличие пор (полости округлой формы). Заметим, что в сжатом материале поры или трещины возникать не могут из-за стесненности, сжатие как раз используется для залечивания несплошностей. Другим доказательством высокой температуры внутри полосы сдвига авторы [15] считают наличие ступенек на поверхности кратера, от которых идут узкие полосы сдвига. При ударе массивного шара в экспериментах [15] причиной образования ступенек на поверхности кратера является периодический выход ударной волны на свободную поверхность перед границей контакта, когда скорость перемещения последней становится дозвуковой. Последующее ударное воздействие шара на выступ приводит к образованию тонкой полосы адиабатического сдвига. Такой механизм образования полос сдвига известен для сварки взрывом [16].

Нет обоснованного доказательства теплового разупрочнения материала, являющегося необходимым условием образования полос локализованной деформации: прохождение полос локализованной деформации через материал без видимого деформированного состояния $[17,18]$, обнаружение пор и трещин внутри полос деформации $[10,19]$, высокая микротвердость в полосах стальных образцов по сравнению с окружающим материалом $[7,20]$. Полосы адиабатического сдвига (синоним полос локализованной деформации) в титановых образцах на 25\% более твердые, чем недеформированный материал [15]. После воздействия сходящихся ударных волн микротвердость в полосах деформации титанового сплава увеличивалась в $1.2-1.5$ [21]. Не удалось обнаружить термическое разупрочнение в экспериментах [22], несмотря на высокую степень деформации (570\%), и температуру $\left(530^{\circ} \mathrm{C}\right)$. Авторы недоумевают - какая причина могла привести к локализации деформации, если разупрочнение отсутствует.

Как следует из проведенного анализа, несмотря на обилие литературы, надежных данных, подтверждающих наличие высокой температуры (или разупрочнения), нет. Образование полос адиабатического сдвига при криогенных температурах еще раз этому подтверждение.

\section{Волновая (откольная) модель локализации деформации}

Откольная природа локализации пластической деформации обоснована многочисленными взрывными экспериментами по переходу откольных трещин (плоские, угловые, канальные, иглоподобные, радиальные, цилиндрические) в полосы локализованной деформации [2327]. Откол - это динамическое разрушение материала в местах встречи волн разгрузки. Полосы, по существу, являются незавершенными откольными трещинами, поскольку возникают в зонах интерференции волн разгрузки, где напряжение растяжения не превышает динамической прочности материала, и сплошность материала сохраняется. Волновая модель локализации деформации принципиально отличается от термомеханической модели тем, что причиной локализации является высокоскоростное растяжение материала, а не тепловое разупрочнение.

Волновая (откольная) модель локализации деформации позволила сформулировать условия зарождения и развития процесса локализации, прогнозировать появление полос адиабатического сдвига (синоним полосы локализованной деформации), определять места возникновения будущей полосы локализации, т.е. решить те проблемы, которые не смогла решить термомеханическая модель локализации.

\section{Замечание о рекристаллизационном механизме локализации пластической деформации}

Многочисленные исследования полос адиабатического сдвига, полученных на установках разрезного стержня Гопкинсона, обнаруживают в них рекристаллизованные субзерна и равноосные зерна похожего размера $0.05-0.3 \mu \mathrm{m}$ в диаметре [7,10,28]. Принято считать, что рекристаллизация является неотъемлемым свойством полос сдвига при скоростях удара порядка $10 \mathrm{~m} / \mathrm{s}$, 
давлении 0.1-0.3 ГПа, длительности нагружении до $100 \mu \mathrm{s}$ [28]. В работе [1] экспериментально показано, что динамическая рекристаллизация может возникать только на стадии сжатия до момента разгрузки, и требует высоких степеней деформирования. Детальный анализ полос адиабатического сдвига $[7,28]$ показал, что зерна ферритной стали $0.2-0.3 \mu \mathrm{m}$ удлиняются в процессе динамического кручения, и их ширина уменьшается от $1 / 2$ до $1 / 3$, а средняя степень деформации может достигать $1000 \%$.

Обращает внимание тот факт, что процессы рекристаллизации не наблюдаются при взрывном (высокоскоростном) нагружении металлов, несмотря на значительно превосходящую разницу в интенсивности нагрузки, создаваемой при использовании взрывчатого вещества и установки Гопкинсона. Анализ, проведенный в [27], показал, что рекристаллизация при низкоскоростном нагружении возникает в режиме мегапластической деформации при запредельных степенях деформации [29]. Такая деформация подавляет или существенно затрудняет развитие процесса разрушения. Заметим, что при всех видах нагружений (сдвиг, кручение, изгиб, прокатка, гидроэкструзия и т.д.) мегапластическая деформация сопровождается растяжением зерен материала под нагрузкой, что является не характерным для взрывного деформирования. Отсутствие в экспериментальной схеме сжимающих напряжений приводит к традиционному механизму разрушения: формированию микротрещин, их росту, слиянию и окончательному разрушению материала, при этом степень деформация относительно низкая. Ситуация, когда сжимающие напряжения присутствуют при растяжении, не характерна для высокоскоростного нагружения, и скорее является исключением из правил.

Впервые сомнения в универсальности тепловой природы потери устойчивости, приводящей к сдвиговой локализации, были высказаны в работах $[13,14]$. Наблюдения авторов показали, что зародыши рекристаллизации возникают до того, как образуется полоса сдвига, при этом их образование не зависит от теплового разупрочнения, поскольку тепловой адиабатический эффект мал и им можно пренебречь. Авторы рассматривают динамическую рекристаллизацию как процесс, который запускает локализацию, вместо теплового разупрочнения.

\section{Эфффект самозалечивания}

Исследование структуры сохраненных образцов после взрывной обработки проводилось с помощью оптического микроскопа Neophot-30, растрового микроскопа LEO 1450, электронного микроскопа сверхвысокого разрешения Zeiss Ultra Plus. Взрывное нагружение образцов в форме толстостенного полого или сплошного цилиндра осуществлялось ударом тонкой алюминиевой пластины, разогнанной накладным зарядом аммонита 6ЖВ или гексогеном насыпной плотности. Давление

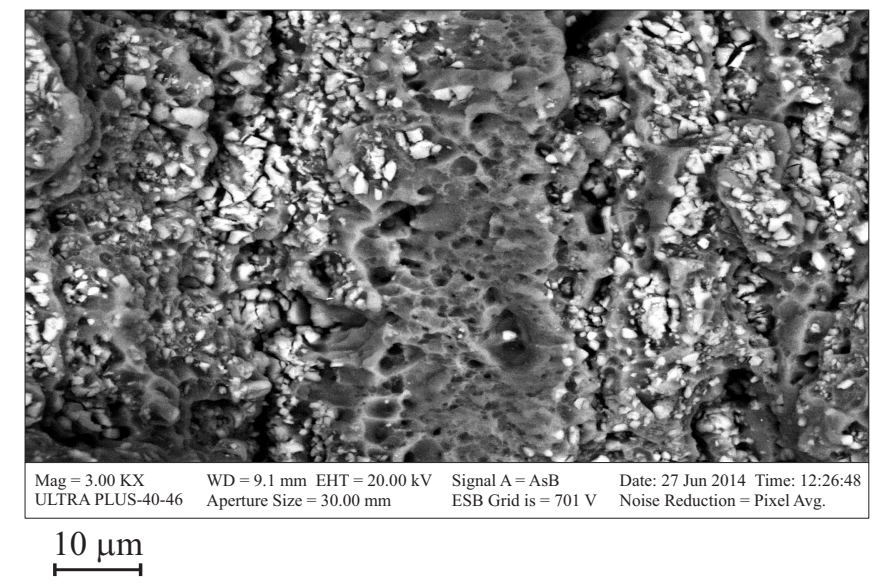

Рис. 1. Микроструктура полосы локализованной деформации в дисперсно-упрочненном алюминиевом сплаве вблизи области перехода откольной трещины в полосу локализованной деформации.

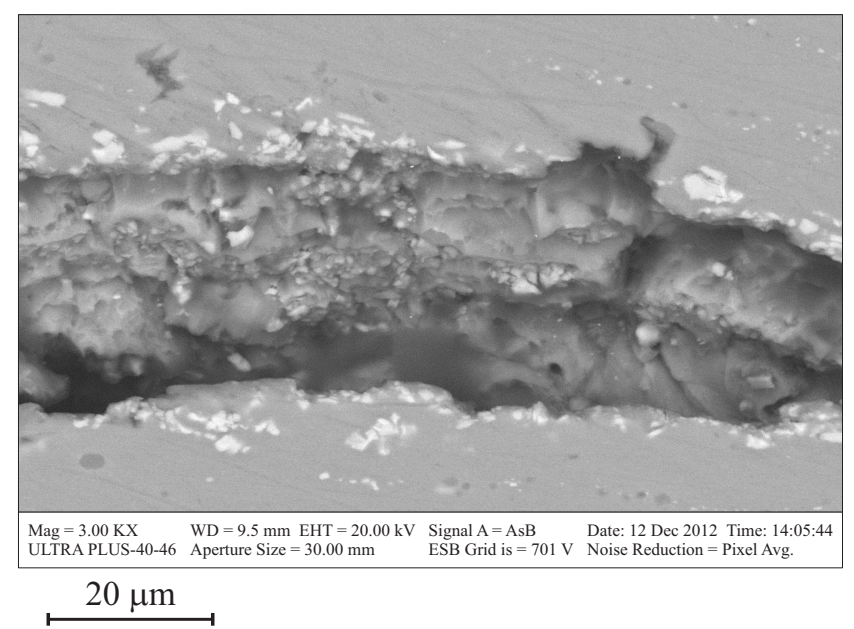

Рис. 2. Фрагментированная микроструктура внутри полосы локализованной деформации.

ударной волны при этом составляло $7-15 \mathrm{GPa}$. Изучение поведения легирующей фазы вблизи полос откольной повреждаемости (трещины и полосы) проводилось на дисперсионно-упрочненном алюминиевом сплаве. Частицы легирующей фазы, содержащие магний, марганец и медь, располагались в образце в виде колоний, сформированных в процессе технологической прокатки. Расстояние между колониями интерметаллидов менялось от 15 до $40 \mu \mathrm{m}$. Индивидуальный размер частиц упрочняющей фазы составлял $0.5-2 \mu \mathrm{m}$, однако многие частицы комковались, образуя конгломераты из множества мелких частиц размером 5-10 $\mu$ m. Рис. 1 демонстрирует микроструктуру в области перехода откольной трещины в полосу локализованной деформации, где напряжение высокоскоростного растяжения близко к динамической прочности материала, это максимально возможная величина, при которой сохраняется сплошность материала. 
Сильно деформированный материал между колоний легирующих частиц представляет собой практически бесструктурную область, содержащую огромное количество микропор, размер которых меняется от 100 до $400 \mathrm{~nm}$. Аналогичная бесструктурная область в зоне перехода трещины в полосу локализации наблюдалась в образцах титана, меди и сталей с перлитоферритной структурой. Микропоры, зародившиеся непосредственно в процессе деформирования, являются зародышами очагов разрушения, которые в процессе деформирования образуют вскрытые микропустоты классического ямочного типа с размером 1-3 $\mu \mathrm{m}$. Авторы [19] считают, что микропоры возникают в результате объединения вакансий. Избыток вакансий является атрибутом откольного разрушения. Теоретические оценки размера несплошностей для дисклинационного механизма образования зародышевой микропоры дают размер пор порядка $0.1 \mu \mathrm{m}$ [30]. Обращает внимание на рис. 1 изменение размера многих легирующих частиц вблизи границы с алюминиевым сплавом, их размер снижается до $0.2 \mu \mathrm{m}$, что свидетельствует о перестройке структуры в результате их частичного растворения. На рис. 2 показана фрагментированная микроструктура внутри полосы локализованной деформации. Высокие степень и скорость деформации в зоне интерференции волн разгрузки приводит к сильному измельчению материала, что хорошо видно в центральной части полосы. Согласно представлениям В.В. Рыбина [31], основанным на дисклинационной моде деформации, размер фрагментов может уменьшаться до минимальной предельной величины $0.20-0.25 \mu \mathrm{m}$, который возникает непосредственно перед разрушением. Рис. 2 демонстрирует скопление легирующих частиц вблизи полосы локализованной деформации. Сегрегация частиц на полосах откольной повреждаемости является характерной особенностью процесса локализации деформации в упрочнено-дисперсионных сплавах алюминия. Скопление частиц в полосах деформации свидетельствует о миграции частиц из матричного материала к местам откольной повреждаемости. Толщина слоя, из которого поступают ультратонкие частички к области растущего разрушения, составляет $10-20 \mu \mathrm{m}$ для полос, пересекающих колонии упрочняющей фазы. Прохождение полос деформации вдоль колоний приводит к миграции частиц с более близкого расстояния до $10 \mu \mathrm{m}$ (рис. 3).

В сталях с перлитоферритной структурой наблюдается массоперенос углерода. Основной структурной составляющей низкоуглеродистой стали являются зерна феррита со средним размером около $50 \mu \mathrm{m}$. Зерна перлита располагаются колониями вдоль направления технологической прокатки прутка. Расстояние между колониями перлита меняется от 15 до $50 \mu \mathrm{m}$. Длина цементитных пластин в перлите составляла $2-3 \mu \mathrm{m}$, отношение длины к ее толщине 30 , межпластиночное расстояние $0.15 \mu \mathrm{m}$. На рис. 4 показана полоса локализованной деформации в стальном образце после травления, в результате чего материал приобретает

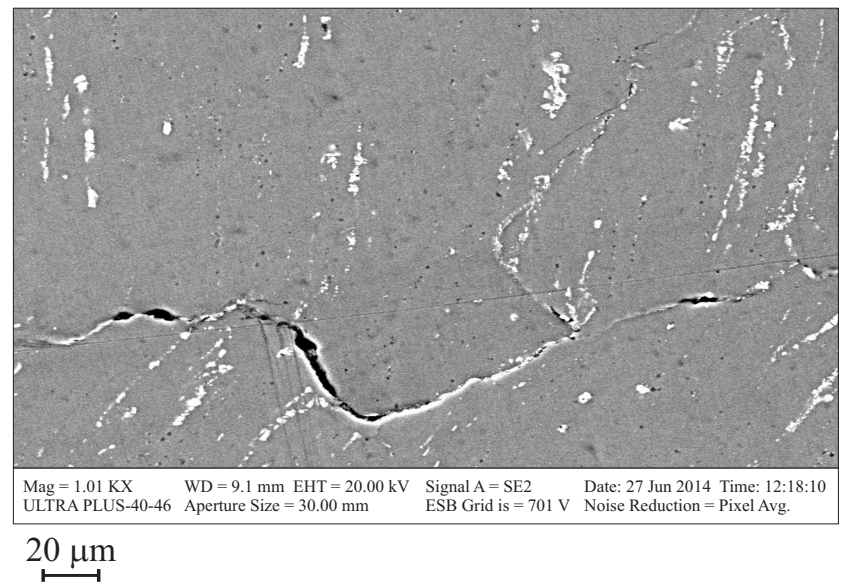

Рис. 3. Особенности прохождения полос деформации вдоль и поперек колоний частиц упрочняющей фазы.

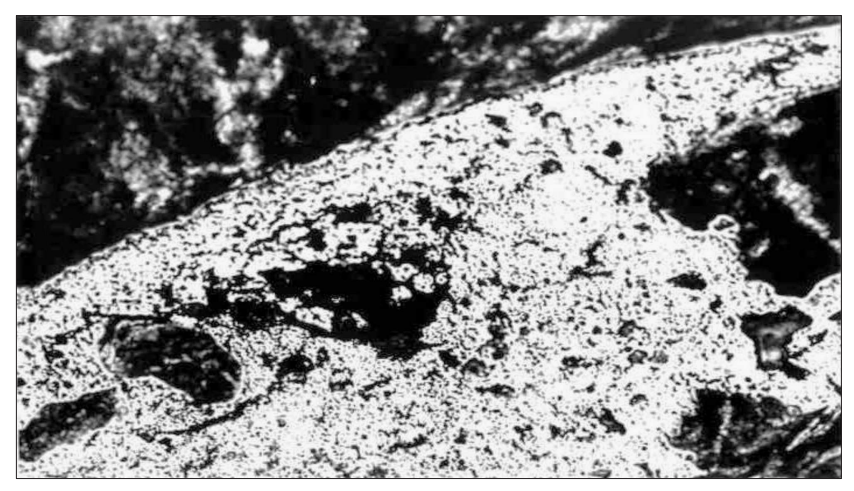

Рис. 4. Белотравленная полоса в стальном образце $(\times 500)$.

белый цвет. Пластины исходного перлита в белотравленных полосах сильно фрагментированы, в ультратонких размер фрагментов способствует перераспределению углерода между карбидной и ферритной фазами. Энерго-дисперсионный анализ стального образца на углерод (метод материального контраста) обнаружил вблизи зоны откольной повреждаемости слой толщиной $20-40 \mu \mathrm{m}$, обедненный углеродом, и очень тонкий слой, непосредственно примыкающий к зоне разрушения, обогащенный углеродом. Измерение микротвердости в [7] обнаруживает области с пониженной микротвердостью толщиной $50 \mu \mathrm{m}$ по обе стороны от полосы деформации, в то время как сама полоса проявляет повышенную микротвердость. Аналогичный результат подтвержден в [32]. Однако снижение микротвердости в областях, примыкающих к полосам локализации, авторы $[7,32]$ объясняют традиционно термическим влиянием. Как следует из наших данных энерго-дисперсионного анализа, в работах $[7,32]$ наблюдали области с пониженным содержанием углерода. Известно, что микротвердость в сталях зависит от содержания углерода и изменяется практически линейно, уменьшаясь примерно на 80 единиц на каждые $0.1 \%$ (по массе) снижения содержания 


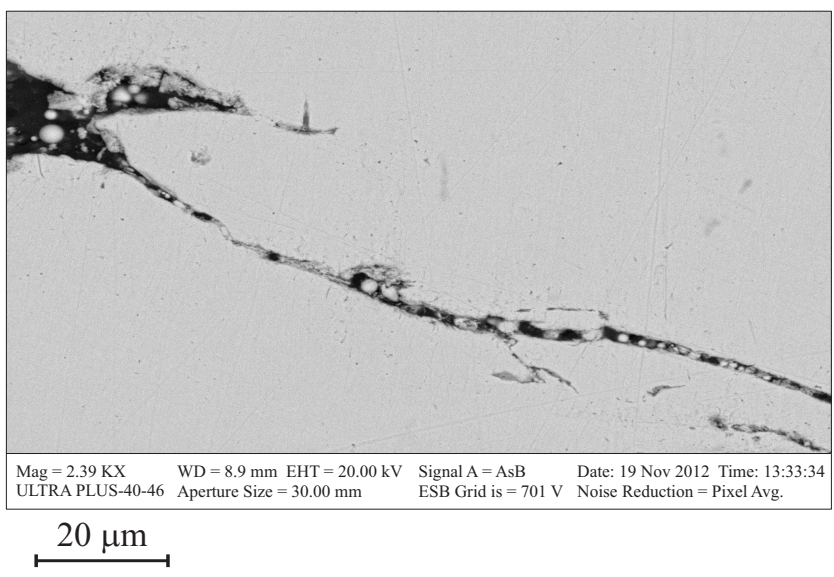

Рис. 5. Образование сфероидального цементита в полосах локализованной деформации при амплитуде ударной нагрузки в $11.8 \mathrm{GPa}$.

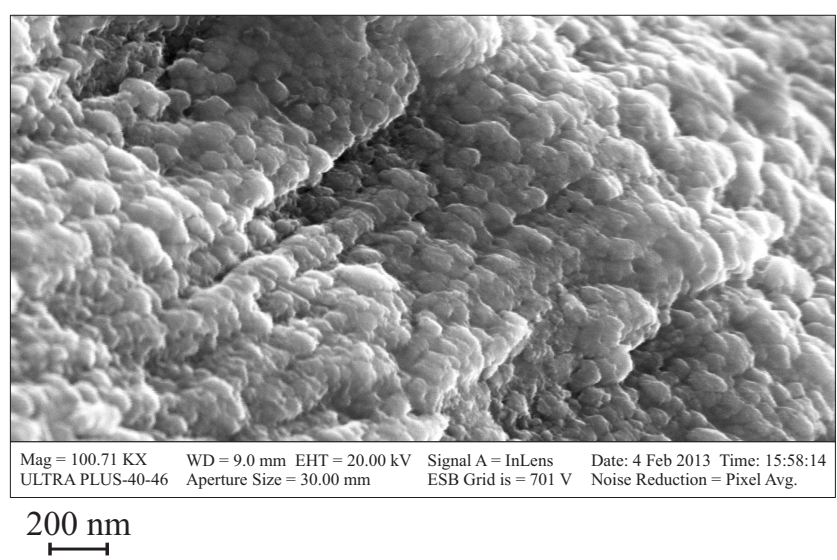

Рис. 6. Образование зародышей оксида меди на фрагментах внутри откольной трещины в медном образце.

углерода [32]. Наличие обедненного слоя свидетельствует о массопереносе углерода из прилегающей зоны матричного материала к областям повреждаемости. Поставка атомов углерода из матрицы в зону откольной повреждаемости увеличивает содержание углерода в зоне локализации. В белотравленных полосах адиабатического сдвига обнаружен метастабильный карбид $\chi \mathrm{Fe}_{3} \mathrm{C}_{2}[20]$. Тот факт, что метастабильный карбид сохраняет кристаллическую структуру $\mathrm{Fe}_{3} \mathrm{C}$, свидетельствует о наличии свободного углерода. С ростом амплитуды импульсной нагрузки микроструктура (рис. 5) в полосах локализованной деформации изменяется. В полосе обнаруживается большое количество сфероидального цементита. По-видимому, изменение динамического режима нагружения привело к дополнительной карбидизации ферритной фазы и перестройке внутренней структуры материала.

На рис. 6 приведена фотография микроструктуры полос локализованной деформации медного образца. Раздробленные фрагменты металла оказались покры- тыми ультратонкими частицами шишкообразного вида, размер которых не превышает $100 \mathrm{~nm}$. Такой вид микроструктуры часто наблюдается в титане, алюминии, низкоуглеродных сталях. Объяснение образования мелкодисперсного покрытия с гладкими шарообразными поверхностями дано в [19]. Частицы оказались зародышами оксидов меди. Авторы [19] предполагают, что в процессе высокоскоростной деформации кислород, растворенный в металле при его промышленном изготовлении, мигрирует из матричного материала к местам локализации пластической деформации.

Таким образом, приведенные экспериментальные данные о массопереносе элементов внедрения $(\mathrm{O}, \mathrm{C})$, дисперсных частиц легирующей фазы из матричного материала в зону формирования откольной повреждаемости, перестройка структуры материала внутри полосы локализованной деформации свидетельствуют о том, что при импульсном высокоскоростном деформировании в материале возникает защитная реакция в виде образования эффекта самозалечивания.

\section{Оценка времени миграции „строительного“ материала}

Представляет интерес оценить время действия эффекта самозалечивания как механизма поставки „строительного материала“ к местам повреждаемости. Полоса локализованной деформации возникает в зоне интерференции волн разгрузки, источниками которых являются свободные поверхности (грани образца). Ширина зоны интерференции волн мала и равна $2 b s_{0}, \quad\left(s_{0}=u_{0} / c_{0}-\right.$ отношение массовой скорости к скорости звука, $c_{0}$ и $b-$ параметры адиабаты материала). Длительность нахождения материала при отрицательном давлении определяется моментами встреч головных $\tau_{1}=c_{0} t / \delta=\left(1+(2 b-1) s_{0}\right)^{-1} \quad$ и хвостовых характеристик $\tau_{2}=\left(1-s_{0}-1\right) \quad(\delta-$ расстояние между источниками волн разгрузки). Волновые процессы, сопровождающие образование полос локализованной деформации, характеризуются взаимодействием волн разгрузки между собой и с гранями образца, что приводит к осцилляции напряжения в образце. Если нарушение сплошности в зоне интерференции отсутствует, возникают стоячие волны внутри образца, при этом сохраняется некоторое количество энергии, и процесс может продолжаться без действия внешних сил. Такая ситуация имеет место в откольной пластине (тарелочке), отделяющейся от образца при отколе. Рассмотрение волновой картины формирования полос локализации [33] на $x-t$ (путь-время) диаграмме показывает, что в зоне интерференции волн происходит периодическая смена процессов растяжения и сжатия. Примыкающий к зоне локализации матричный материал „дышит“, подвергаясь периодическому сжатию и разгрузке до нулевого давления. Поглощение энергии при реверберации 
происходит в результате взаимодействия волн со средой. Диссипативные процессы - вязкость и теплопроводность - создают дополнительный негидродинамический перенос импульса и энергии, что приводит к необратимому превращению механической энергии в тепло. Во всех случаях поглощение энергии приводит к ослаблению амплитуды волны по экспоненциальному закону. Коэффициент затухания $\alpha$ характеризуется долей энергии $E$, которая поглощается в единице времени. Изменение энергии во времени описывается выражением $d E / d t=-\alpha E$, следовательно, $E=E_{0} \operatorname{exp-}$ $-\alpha t$. Амплитуда стоячей волны затухает со временем по закону $\exp (-\alpha t / 2)$. Оценить коэффициент затухания $\alpha$ можно используя геометрическую интерпретацию законов сохранения, как это сделано в [8]. Через каждые половину периода цикла реверберации $T_{0}=$ $=\delta / c_{0}$ массовый поток меняет свое направление на обратный, при этом происходит снижение скорости вследствие затухания амплитуды волны. Поэтому частица перемещается к зоне повреждаемости со скоростью, равной разности скоростей $\Delta u=u-u \exp \left(-\beta \delta / c_{0}\right)=$ $=u\left[1-\exp \left(-\delta / x^{*}\right)\right]=u \delta / x^{*}, \quad$ где $\beta=\alpha / 2-$ коэффициент затухания амплитуды волны, $T_{0}=\delta / c_{0}$ - полупериод реверберации, $x^{*}-$ пространственный период, на котором амплитуда стоячей волны затухает в $e$ раз, $u=u_{0} \exp (-\beta t)-$ закон затухания скорости. Уравнение траектории мигрирующей частицы принимает вид $d x / d t=\left(u_{0} \delta / x^{*}\right) \exp (-\beta t)$, решением которого при начальных условиях $x_{0}=0$ и $t_{0}=0$ является $x=$ $=\left(u_{0} \delta / x^{*} t\right)$. Считая, что толщина стального образца $\delta=10 \mathrm{~mm}$, динамическая прочность $P=1.5 \mathrm{GPa}$, а коэффициент затухания $\alpha=0.023 \mu \mathrm{s}^{-1}$, определенный по $x-t$-диаграмме, длительность процесса реверберации равна $t^{*}=1 / \beta \approx 90 \mu \mathrm{s}\left(x^{*}=c_{0} / \beta \approx 400 \mathrm{~mm}\right)$. Скорость перемещения мигрирующего углерода равна $\beta u_{0} \delta / c=$ $=0.001 \mathrm{~mm} / \mu \mathrm{s}=1 \mu \mathrm{m} / \mu \mathrm{s}$, тогда путь, который может пройти частичка в процессе реверберации равен $90 \mu \mathrm{m}$. По экспериментальным данным толщина слоя, с которого углерод мигрируют, равна $l \sim 40 \mu \mathrm{m}$. Длительность процесса залечивания, т. е. время массопереноса углерода к повреждаемой зоне, составляет половину времени циркуляции волн в образце. Слабое затухание волн при реверберации приводит к значительному увеличению времени действия импульсного нагружения образца. Длительность начального импульса зависит от толщины пластины-ударника, и в эксперименте составляла $0.65 \mu \mathrm{s}$. Время миграции легирующих микрочастиц и элементов внедрения оказалось на два порядка больше времени действия начального импульсного нагружения.

\section{Заключение}

Массоперенос дисперсных частиц легирующей фазы, элементов внедрения $(\mathrm{O}, \mathrm{C})$ из матричного материала в зону формирования откольной повреждаемости, а так же перестройка внутренней структуры в результате процессов окисления и карбидизации внутри полос локализации - процессы, которые характеризуют эффект самозалечивания. При высокоскоростном растяжении нарушается исходная равновесная система, меняется давление, температура, фазовый состав, концентрация легирующих частиц. Изменение характеристик материала усиливает процессы сопротивления материала разрушению, материал стремится залечить растущее разрушение. При динамических нагрузках ответная реакции материала на внешнее воздействие (принцип Ле Шателье) проявляется в виде эффекта самозалечивания, который направлен на компенсацию происходящих изменений в материале. Массоперенос в условиях импульсного деформирования сопровождается реверберацией волн, подобно осцилляции волн в откольных тарелочках. Слабое затухание волн при реверберации увеличивает длительность импульсного нагружения образца практически на два порядка по сравнению с временем начального импульса.

\section{Список литературы}

[1] Nesser S., Chang S.-N. // Mech. Mater. 1990. N 10. P. 1-17.

[2] Петров А.И., Разуваева М.В., Синани Д.Б., Никитин В.В. // ЖТФ. 1998. Т. 68. Вып. 11. С. 125-127.

[3] Петров А.И., Разуваева М.В. // ЖТФ. 2003. Т. 73. Вып. 6. C. $53-55$.

[4] Малышев А.Н., Замотаев Д.Н., Игнатова О.Н. // Сборник тезисов докладов Междун. конф. „15 Харитоновские тематические научные чтения“ Саров: РФЯЦ-ВНИИЭВб 2013. C. $198-199$.

[5] De Carli P.S., Meyers M.A. Shock Waves and High-StrainRate Phenomena in Metals. Ed. by Meyers M.A., Murr L.E. N.J., London: Plenum Press, 1981. P. 9-29.

[6] Meyers M.A., Хu Y.B., Xue Q., Perez-Prado M.T., McNelley T.R. // Acta Mater. 2003. Vol. 51. P. 1207-1325.

[7] Hwang B., Lee S., Kim Y.C., Kim N.J., Shin D.H. // Mater. Sci. Eng. A.-Struct. 2006. Vol. 441. P. 308-320.

[8] Grady D.E., Asay J.R. // J. Appl. Phys. 1982. Vol. 53. N 11. P. 7350-7354.

[9] Wang Xue bin. // Trans. Nonferrous Met. Soc. China. 2004. Vol. 14, N 6. P. $1062-06$.

[10] Lins J.F.C., Sandim H.R.Z., Kestenbach H.-J., Raabe D., Vecchio K.S. // Mater. Sci. Eng. A.-Struct 2007. Vol. 57. N 1, 2. P. 205-218.

[11] Chen D.N., Fan C.L., Xie S.G., Hu J.W., Wu S.X., Wang H.R., Ta H., Yu Y.Y. // J. Appl. Phys. 2007. Vol. 101. N 6. P. 205-218.

[12] Rittel D., Wang Z.G. // Mech Mater. 2008. N 40. P. 629-635.

[13] Rittel D., Landau P., Venkert A. // Phys. Rev. Lett. 2008. N 101. P. 165501-05.

[14] Rittel D., Osovski S. // Int. J. Fracture. 2010. N 162. P. 177-185.

[15] Timothy S.P., Hutchings I.M. // Acta Metall. 1985. N 33. P. 667-676.

[16] Беликова А.Ф., Буравова С.Н. // Изв. Вол. ГТУ. 2010. № 5 (65). C. 83-87.

[17] Woodward R.L. // Int. J. Mech. Sci. 1978. Vol. 20. N 9. P. 599-607. 
[18] Stock T.A.C., Thomson K.R.L. // Metall. Trans. 1970. Vol. 1. P. $219-224$

[19] Tang N.-Y., Niessen P., Pick R.J. // Mater. Sci. Eng. A.-Struct. 1991. Vol. 131. P. 153-160.

[20] Wittman C.L., Meyers M.A., Pak H.R. // Metall. Trans. A. 1990. Vol. 21. P. 707-716.

[21] Хомская И.В.. Зельдович В.И., Литвинов Б.В., Пурыгин И.П. // ФММ. 2004. Т. 98. № 4. С. 88-95.

[22] Moss G.L. Shock Waves and High-Strain-Rate Phenomena in Metals. / Ed. by M.A. Meyers, L.E. Murr. N.Y., London: Plenum Press, 1981. P. 299-312.

[23] Беликова А.Ф., Буравова С.Н., Петров Е.В. // ЖТФ. 2013. Т. 83. Вып. 8. С. 68-75.

[24] Беликова А.Ф., Буравова С.Н., Гордополов Ю.А. // ЖТФ. 2013. Т. 83. Вып. 2. С. $153-155$.

[25] Буравова С.Н. Этюды на тему локализации динамической деформации. Saarbrücken, Germany: Palmarium Academic Publishing, 2014. 148 p.

[26] Буравова С.Н., Петров У.В., Щукин А.С. // Физика горения и взрыва. 2016. Т. 52. № 5. С. 1-10.

[27] Буравова С.Н., Петров Е.В., Сачкова И.В., Щукин А.С. // Химическая Физика. 2016. Т. 35. № 5. С. 61-68.

[28] Hines J.A., Vecchio K.S. // Acta mater. 1997. Vol. 45. N 2. P. 635-642.

[29] Глезер А.М., Метлов Л.С. // ФТТ. 2010. Т. 52. Вып. 6. C. 1090 .

[30] Бетехтин В.И., Кадомиев А.Г. // ФТТ. 2005. Т. 47. Вып. 5. C. 801-807.

[31] Рыбин В.В. Большие пластические деформации и разрушение металлов. М: Металлургия 1986. 224 с.

[32] Rogers H.C., Shastry C.V. Shock Waves and High-StrainRate Phenomena in Metals / M.A. Meyers, L.E. Murr N.J., London.: Plenum Press, 1981. P. 285-293.

[33] Буравова С.Н., Петров Е.В., Алымов М.И. // ДАН. 2016. T. 469. № 1. C. $1-4$. 